\title{
World Journal of Surgery Welcomes Dr. Timothy Craig Hardcastle as Associate Editor
}

\author{
John G. Hunter ${ }^{1}$
}

Published online: 20 September 2017

(C) Société Internationale de Chirurgie 2017

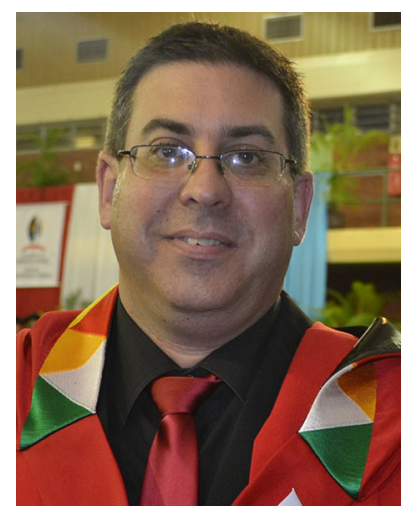

The World Journal of Surgery is delighted to introduce our newest associate editor. Dr. Timothy Craig Hardcastle (MBChB, MMed(Chir), FCS(SA), Ph.D.(UKZN) is a registered Trauma and Critical Care Surgeon. He is the Deputy Director of Trauma and Trauma ICU at the Inkosi Albert Luthuli Central Hospital in Durban, Kwazulu-Natal and head of the Trauma Fellowship Training Program of the Nelson R Mandela School of Medicine at the University of Kwazulu-Natal. He holds the degrees $\mathrm{MBChB}$ and

MMed (Chir) from Stellenbosch University in Cape Town, South Africa and is a specialist Fellow of the College of Surgeons of South Africa. He has published over 85 peerreviewed articles and more than 20 book chapters in the field of trauma, critical care, prehospital care and trauma systems. He is a past President of Trauma Society of South Africa and is the current chair of the Accreditation Committee of the Trauma Society of South Africa. Dr. Hardcastle is an active member of the International Association of Trauma and Surgical Intensive Care (IATSIC) and has been an editor of the World Journal of Surgery for the past 6 years. As well, he is a member of the international faculty of the Definitive Surgical Trauma Care $\left(\mathrm{DSTC}^{\mathrm{TM}}\right.$ ) and teaches on a number of short courses in trauma or emergency care. He has interest in the military history of the Second World War. In May 2017, Dr. Hardcastle was the guest editor of a superb symposium in the WJS on the care of the injured patient. We are grateful for past contributions and excited to the many future contributions of Dr. Hardcastle to the World Journal of Surgery.

John G. Hunter

hunterj@ohsu.edu

1 Portland, OR, USA 